\title{
Dreaming of clean nukes
}

\section{Can the Pentagon defend its plans for new nuclear bombs?}

\section{Michael A. Levi}

Is the US nuclear arsenal sufficient to address today's security challenges? The Pentagon apparently thinks not. A new report ${ }^{1}$ from its Defense Science Board (DSB) argues that "nuclear weapons are needed that produce much lower collateral damage". It lends support to proposals to build new nuclear weapons for attacking underground facilities. To a point, such 'bunker busters' are nothing new - the B-53 bomb, first deployed in the early 1960s, can destroy underground targets, although it creates lethal radioactive fallout that covers hundreds of thousands of square kilometres. The new proposals promise more effective weapons with reduced fallout. But the DSB overstates the extent to which that is possible, and gives the comparative potential of conventional weapons short shrift.

The US Department of Energy insists that, for now, it wants to research, but not build, exotic new weapons. It contends that this is aimed at sustaining design expertisebut there are reasons for doubt. The Bush administration's Nuclear Posture Review ${ }^{2}$, leaked in March 2002, described an aggressive approach to nuclear arms, suggesting a possible need for new nuclear weapons, and the DSB openly discusses deployment.

So far, Congress has been sceptical and has cut funding for nuclear weapons ${ }^{3}$, but the DSB study could change that. In captivating detail, it describes how new nuclear weapons could supercharge US military capabilities. Policy-makers should be wary of these recommendations, however, as the claims are flimsier than they first appear.

The DSB study begins with impressive proposals for improving non-nuclear bunkerbusting weapons. Indeed, for what some have argued only nukes can do, the DSB offers nonnuclear options that might work just as well. The study then goes on to build a case for how new nuclear bombs could destroy buried facilities without killing many people nearby. The unprecedented length and detail of this case is welcome. But it also exposes critical flaws.

The modern bunker buster depends on a missile that penetrates the ground before its payload - nuclear or conventional explodes. Detonating a nuclear weapon underground increases its effectiveness, thereby reducing the size of the bomb needed. If an explosion is deep and small enough, it may be 'contained' below the surface, preventing radioactive fallout. The study concludes that a 100-tonne nuclear bomb that penetrates 30-50 metres underground before detonation could be fully contained. The same goes for a

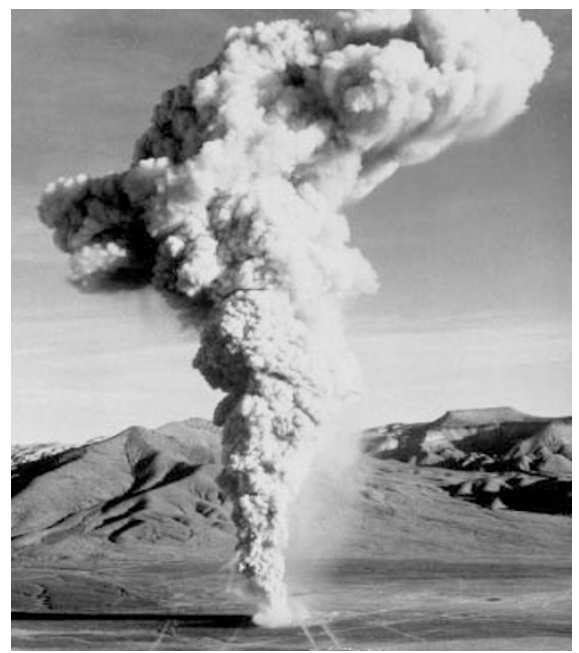

Containing underground explosions is not easy.

400-tonne bomb penetrating 50-55 metres, and a 3,000-tonne bomb penetrating 100 metres $^{1}$. Each of these, the DSB claims, would destroy facilities roughly twice as far underground as the bomb would initially penetrate.

Those conclusions are unsound. The study applies data ${ }^{4}$ that were generated by nuclearweapons tests in Nevada during the cold war. But in the Nevada tests, the hole above the bomb was carefully sealed to prevent falloutin contrast, an earth-penetrating nuclear weapon would leave a large hole behind it, making containment difficult or impossible ${ }^{5}$.

In addition, any claims about containment depend on the geology of the target area, but the DSB is not explicit about its choice of targets - implying that its conclusions are more universal than they actually are. For example, the standard rule for determining burial depth from the Nevada tests - the one the DSB seems to use - is valid for rock with low water content. But for explosions in more hydrous rocks the weapon would have to be buried deeper to contain the fallout ${ }^{5}$.

The destructive potential that the study claims is also suspect. The DSB requires that the explosion disable, not destroy, the contents of a 'hardened' underground facility. This is determined as requiring a shock pressure of 500 bars at the target. But this might not harm enemy leaders or their stored weapons stockpiles $^{6}$. There is a contradiction here. The study claims that the inability of conventional weapons to deliver destruction is the main reason for needing nuclear arms. But to achieve nuclear destruction - rather than disablement - at the same distances, the bomb's power would have to increase 5- to 15 -fold, making containment impossible. By seeking a fallout-free design, the study must accept a
$50 \%$ or more reduction in destructive radius. But if a 'containable' nuclear bomb would deliver such reduced destructive power, might designers not better focus on delivering a conventional warhead to greater depths instead?

This leads us to a third problem: the penetration depths that the DSB promises are either overly optimistic ${ }^{4}$ or oddly cautious. Unstated assumptions about the targets can be misleading. Simply because a device can penetrate 30 metres in limestone, it does not mean that it will do so in harder granite. Elsewhere, the study looks at how multiple bombs dropped into the same hole can make the hole deeper, but ignores the possibility that this will make containment more difficult.

And when the study proposes convincing methods for increasing penetration, it begs an unanswered question. Can these techniques improve penetration of conventional weapons even further ${ }^{7}$, rendering a nuclear warhead unnecessary? At one point, the study explains how a nuclear weapon that penetrates 50 metres can destroy targets 100 metres underground, and later on the same page asserts that a different missile might get 100 metres underground - presumably making the first weapon obsolete. Indeed, in its zeal to concoct penetration strategies that might contain kilotonne-size bombs, the study strengthens the case for using conventional weapons instead.

This is the essence of the debate. For years, nuclear-weapon scientists have been immensely creative in dreaming up groundpenetration schemes to make nuclear weapons powerful yet clean. Most of these ideas will never work, yet they continue to be tolerated. Meanwhile, designers of conventional arms are subject to intense competition and scrutiny. It is no surprise that nuclear weapons sometimes seem to have unlimited potential. But if they are judged by the same standards as other weapons, the case in their favour is much harder to make.

Michael A. Levi is at the the Brookings Institution, 1775 Massachusetts Ave NW, Washington DC 20036, USA.

\footnotetext{
1. Report of the Defense Science Board Task Force on Future Strategic Strike Forces (Department of Defense, Washington DC, 2004) online at www.fas.org/irp/agency/dod/dsb/fssf.pdf

2. Nuclear Posture Review (US Departments of Defense and Energy, Washington DC, 2001).

3. Kucia, C. Arms Control Today 33, (No. 7$) 37$ (2003).

4. Nelson, R. W. Sci. Global Secur. 10, 1-20 (2002).

5. Glasstone, S. \& Dolan, P. J. (eds) The Effects of Nuclear Weapons 3rd edn, 261 (Departments of Defense and Energy, Washington DC, 1977).

6. May, M. M. \& Haldeman, Z. Effectiveness of Nuclear Weapons against Buried Biological Agents 19 (Stanford University, Palo Alto, 2003).

7. Levi, M. A. Fire in the Hole: Nuclear and Non-Nuclear Options for Counterproliferation (Carnegie Endowment for International Peace, Washington DC, 2002).
} 